\title{
TERRITÓRIO E CURRÍCULO: RELAÇÕES INTERDISCIPLINARES ENTRE ESTUDOS TERRITORIAIS E EDUCAÇÃO SOCIAL
}

\author{
Maria Celeste Reis Fernandes de Souza* \\ Ludmylla Karinne Trigueiro Meireles** \\ Maria Gabriela Parenti Bicalho**
}

\begin{abstract}
RESUMO
As discussões apresentadas neste artigo se sustentam nos resultados de uma investigação, de cunho bibliográfico, que buscou estabelecer conexão interdisciplinar entre o campo da geografia, no qual os estudos territoriais se estabelecem, e o campo da educação social. O objetivo dessas discussões é propor reflexões sobre o território e a educação social, e suas contribuições para as práticas curriculares em espaços não escolares. Sob a ótica das teorias críticas, que negam a neutralidade do currículo, buscase explicitar os vínculos que se estabelecem entre conhecimento, relações (sociais e de poder) e conscientização, considerando a espacialidade como constitutivas dessas relações. Nas experiências de educação que se constituem em espaços não escolares (e escolares), os sujeitos são os atores centrais para a construção do currículo, como portadores, nas práticas educativas, de vividos territoriais. As conclusões do estudo apontam para a importância de se considerar o território como constituinte dos sujeitos e, portanto, como constituinte das práticas educativas e elemento a se considerar no campo da pesquisa em educação, especialmente na educação social.
\end{abstract}

Palavras-chave: Currículo. Educação social. Território.

\begin{abstract}
TERRITORYAND CURRICULUM: INTERDISCIPLINARY RELATIONSHIPS BETWEEN TERRITORIAL STUDIES AND SOCIAL EDUCATION

The discussions presented in this article are supported by the results of a bibliographic investigation that seeks to establish an interdisciplinary connection between the field of geography, which encompasses territorial studies, and the field of social education. The purpose of these discussions is to offer reflections concerning territory and social education, and their contributions to curricular practices in non-school spaces. From the perspective of critical theories that deny the neutrality of curriculums, we seek to clarify
\end{abstract}

\footnotetext{
* Doutora em Educação pela Universidade Federal de Minas Gerais (UFMG). Pós-Doutoranda em Educação pela Universidade Federal de Sergipe. Endereço para contato: Av. Rio Doce, 2449, Ilha dos Araújos - Governador Valadares-MG. CEP: 35020500. celeste.br@gmail.com

** Graduada em Pedagogia. Estudante do Curso de Pós-graduação Lato Sensu em Psicopedagogia na Universidade Estadual do Rio de Janeiro (UERJ). Endereço para contato: Rua Pedro de Carvalho, nº 750, Ap. 201 (Fundos) - Lins de Vasconcelos. Rio de Janeiro-RJ. CEP: 20725-233. meireleslkt@gmail.com

*** Doutora em Educação pela Universidade Federal de Minas Gerais (UFMG). Professora Adjunta do Departamento de Medicina. Universidade Federal de Juiz de Fora. Campus Avançado Governador Valadares. Endereço para contato: Rua Tiradentes, 199, apt. 1001 - Esplanada. Governador Valadares-MG. CEP: 35020-610. maria.gabriela@ufjf.edu.br
} 
the links that exist between knowledge, (social and power) relations, and awareness, considering spatiality as constitutive of these relations. In terms of educational experiences that occur in non-school (and school) spaces, individual subjects who experienced, first-hand, local educational practices are the main protagonists in the creation of curriculums. The study's findings emphasize the importance of viewing territory as a constituent of the subject. As such, territory is not only a constituent of educational practices, but also an element to be considered in the field of educational research, especially with regards to social education.

Keywords: Curriculum. Social education. Territory.

\section{RESUMEN}

\section{TERRITORIO Y CURRÍCULO: RELACIONES INTERDISCIPLINARIAS ENTRE ESTUDIOS TERRITORIALES Y EDUCACIÓN SOCIAL}

Las discusiones que se presentan en este artículo apoyan los resultados de una investigación bibliográfica que buscó establecer la conexión interdisciplinar entre el campo de la geografía, en el que se establecen estudios territoriales, y el campo de la educación social. El objetivo de estas discusiones es proponer reflexiones sobre el territorio y la educación Social y sus contribuciones a las prácticas curriculares en espacios no escolares. Desde la perspectiva de las teorías críticas que niegan la neutralidad del currículo, tratamos de explicar los vínculos que se establecen entre el conocimiento, las relaciones (sociales y de poder) y la conciencia, teniendo en cuenta la espacialidad como constitutiva de estas relaciones. En las experiencias educativas que están en los espacios no escolares (y escolares), los sujetos son los actores centrales para la construcción del currículo, como los portadores en las prácticas educativas de territorial vivido. Las conclusiones del estudio apuntan a la importancia de considerar el territorio como un constituyente de los sujetos, y por lo tanto, como un constituyente de las prácticas y elementos educativos a considerar en el campo de la investigación en educación, especialmente en la educación social.

Palabras clave: Currículo. Educación social. Territorio.

\section{Introdução}

As discussões que apresentamos neste artigo têm como propósito possibilitar reflexões sobre os estudos territoriais e a educação social, assim como as contribuições interdisciplinares advindas do diálogo entre esses campos de conhecimento, para se pensar as práticas educativas em espaços não escolares, com especial atenção para o currículo como constituinte e constituidor dessas práticas.

Contribuem para essas discussões as experiências construídas em nossa inserção nesses espaços como professoras extensionistas e pesquisadoras: os vínculos com os movimentos sociais do campo e da cidade, e em espaços de privação de liberdade, nos quais a educação tem sido compreendida como um direito, muito recentemente, com a publicação das Diretrizes Curriculares Nacionais para a Educação Prisional (BRASIL, 2010).

Ao abordarmos a educação social, desejamos falar, como nos propõe Gadotti (2012, p. 3), de "uma educação popular, social e comunitária transformadora", que ao buscarem "integrar os sujeitos à sociedade, não o fazem mecanicamente: integram para transformar a sociedade na qual são integrados. Integrar e incluir para emancipar”.

Por sua vez, a necessidade de abordagens interdisciplinares para a compreensão dos fenômenos educacionais tem sido indicada por diferentes pesquisadores do campo educacional que discu- 
tem a identidade epistemológica das Ciências da Educação (CHARLOT, 2006; FRANCO, 2003; PIMENTA, 1998).

Nesse contexto, a interdisciplinaridade tem se feito presente a partir dos anos 1980, seja no sentido de compreender as possibilidades de articulações teóricas entre diferentes campos disciplinares no processo ensino aprendizagem (FAZENDA, 2005) - dimensão pedagógica do conceito -, seja como uma perspectiva epistemológica, a qual possibilita a incorporação desse conceito à prática pedagógica (THIESEN, 2008).

Neste texto, buscamos empreender um estudo interdisciplinar pela construção de diálogo e articulações teóricas entre os campos da Educação e da Geografia; mais especificamente, procuramos trabalhar com conceitos dos estudos territoriais para discutir a educação social. Apostamos assim na fecundidade do conceito de território para a produção de novos saberes acerca dos fenômenos educativos, como têm propiciado a outros campos:

Enquanto o geógrafo tende a enfatizar a materialidade do território, em suas múltiplas dimensões [...], a Ciência Política enfatiza sua construção a partir de relações de poder [...]; a Economia, que prefere a noção de espaço à de território, percebe-o muitas vezes como um fator locacional ou como uma das bases da produção (enquanto 'força produtiva'); a Antropologia destaca sua dimensão simbólica, principalmente no estudo das sociedades ditas tradicionais (mas também no tratamento do 'neotribalismo' contemporâneo); a Sociologia enfoca a partir de sua intervenção nas relações sociais, em sentido amplo, e a Psicologia, finalmente, incorpora-o no debate sobre a construção da subjetividade ou da identidade pessoal, ampliando-o até a escala do indivíduo. (COSTA, 2009, p. 37, grifo do autor).

Nesse sentido questionamos: Que uso pode-se fazer do território para discutir a educação social? De que maneira as reflexões propostas pelos estudos territoriais podem propiciar análises das vivências educativas nesse campo? Que contribuições esse diálogo interdisciplinar propicia para se pensar as diferentes experiências educativas populares?

$\mathrm{Na}$ tentativa de construir respostas a essas perguntas, chegamos às discussões no campo do currículo. As discussões sobre território oferecem um ponto de vista que nos parece bastante profí- cuo para essas reflexões. Chamam a atenção para o fato de que é no território que se configura a vida: a moradia, o trabalho, o lazer, as relações das pessoas entre si e com a natureza, questões essas muito presentes na educação social e, portanto, no currículo vivido nas experiências educacionais.

Modos de vida, relações de poder, identidades e culturas podem ser entendidos como processos de constituição de território. Os estudos territoriais remetem à espacialidade como palco de práticas sociais, nas quais os sujeitos reconstroem paisagens geográficas criativamente, buscando atender suas necessidades. É no "vivido territorial" (RAFESTTIN, 1993), portanto, que também acontece a educação. Colocam-se, então, questões sobre as maneiras pelas quais esse vivido comparece nos currículos em espaços não escolares, convidados ou não, a se fazer presentes nas diferentes práticas educativas.

É, pois, esse conjunto de reflexões que norteia este artigo, que se organiza em três seções. A primeira apresenta o exercício que empreendemos para explicitar o movimento interdisciplinar entre os estudos territoriais e a educação social. A segunda destaca o espaço como elemento a ser refletido nas relações entre território e currículo, uma vez que este se configura como palco de historicidade, cultura, relações, e nele estão impressos signos, identidades, vida. Na última seção, explicitamos indagações motivadas pelas nossas experiências em espaços não escolares e possíveis respostas a essas indagações que, em última instância, nos levam a interrogar as práticas escolares e a pesquisa educacional.

\section{Construindo o movimento interdisciplinar: estudos territoriais e educação social}

\subsection{Situando território}

O movimento interdisciplinar aqui empreendido busca compreender as relações que se estabelecem entre dois diferentes campos de conhecimento: o campo da Geografia e o da Educação Social. Para empreender esse movimento, aportamos a contribuição, inicialmente, de dois autores que buscam resgatar e ressignificar a discussão sobre o espaço e seu lugar na compreensão das práticas humanas: Edward Soja e Doreen Massey. 
Soja (1993, p. 7) propõe a "reafirmação de uma perspectiva espacial crítica na teoria e nas análises sociais contemporâneas", que poderia abrir espaço para uma "hermenêutica espacial", assumindo o desafio de "[...] traduzir em palavras a espacialidade abrangente e politizada da vida social [...]". O autor afirma que a espacialidade foi silenciada pelo historicismo que passou a dominar as ciências sociais a partir das últimas décadas do século XIX, na medida em que o caráter histórico da vida social foi apontado como fundamental para a transformação social e a emancipação dos sujeitos.

Para Soja (1993), as transformações sociais e econômicas levam as pessoas a repensar o modo como vivem, o que inclui suas produções e relações. Desta forma, elas reconstroem seus espaços por serem impelidas a adotar outras formas de viver e de sobreviver.

Assim, o espaço é criativamente caracterizado pelas produções humanas capazes de construir e transformar as paisagens geográficas. Para mostrar que a análise dessa dinâmica foi parcialmente negligenciada pelo historicismo, o que dificultou o reconhecimento da importância do espaço, Soja (1993) vale-se das afirmações de Foucault: "O espaço foi tratado como o morto, o fixo, o não dialético, o imóvel. O tempo, ao contrário, foi a riqueza, a fecundidade, a vida e a dialética" (FOUCAULT, 1980 apud SOJA, 1993, p. 17). Indicando a importância de reconhecer o espaço como referência do ser social, Soja convida-nos a reconhecê-lo como elemento essencial para o estabelecimento das relações na vida social.

Mais de uma década depois, Massey (2007) também argumenta a favor da importância de se considerar o espaço na análise social, e apresenta novos significados para essa discussão. Para ela,

[...] importa o modo como pensamos o espaço; o espaço é uma dimensão implícita que molda nossas cosmologias estruturantes. Ele modula nossos entendimentos do mundo, nossas atitudes frente aos outros, nossa política. Afeta o modo como entendemos a globalização, como abordamos as cidades e desenvolvemos e praticamos um sentido de lugar. Se o tempo é a dimensão da mudança, então o espaço é a dimensão do social: da coexistência contemporânea de outros. (MASSEY, 2007, p.15).
A autora propõe uma abordagem alternativa do espaço, que estaria baseada em três proposições básicas. A primeira refere-se ao reconhecimento do espaço como "produto de inter-relações, como sendo constituído através de interações", não existindo, portanto, antes de "identidades/entidades" (MASSEY, 2007, p. 18) e suas relações. A autora propõe o argumento de que "identidades/entidades, as relações 'entre' elas e a espacialidade que delas faz parte são todas co-constitutivas" (MASSEY, 2007, p. 18, grifo da autora).

A segunda proposição de Massey (2007) está ligada à existência da multiplicidade, da "pluralidade contemporânea", na qual distintas trajetórias coexistem. O espaço deve ser pensado, portanto, como "[...] a esfera da coexistência da heterogeneidade. Sem espaço, não há multiplicidade; sem multiplicidade, não há espaço. Multiplicidade e espaço são co-constitutivos" (MASSEY, 2007, p. 20).

Como consequência dessa proposição, a autora considera que "qualquer reconhecimento sério da multiplicidade e heterogeneidade em si mesmas depende de um reconhecimento da espacialidade" (MASSEY, 2007, p. 22).

A terceira proposição refere-se ao reconhecimento do caráter inacabado do espaço, ao fato de que "[...] ele está sempre no processo de fazer-se. Jamais está acabado, nunca está fechado. Talvez pudéssemos imaginar o espaço como uma simultaneidade de estórias-até-agora" (MASSEY, 2007, p. 29-31). Isso implica na consideração do futuro como também sempre aberto.

A consideração do espaço como elemento constitutivo das práticas e da cultura humana está presente na obra de diferentes autores que utilizam a noção de território. Os primeiros usos do termo, restrito ainda à Geografia, são identificados por Costa (2009) na origem latina do territorium como a denominação de terra. O termo jus terrendi definia um pedaço de terra apropriado nos limites da jurisdição político-administrativa. O autor expõe as definições de território no dicionário Les mots de La Géographie, de Brunet et al (1993): "malha de gestão do espaço"; "espaço apropriado, com sentimento ou consciência de sua apropriação"; "junção jurídica, social e cultural e mesmo afetiva"; "um lugar qualquer" (COSTA, 2009, p. 39). 
Costa (2009) propõe a compreensão do território a partir de três vertentes: política, econômica e cultural ou simbólica. A vertente política faz referência às relações gerais ou institucionalizadas de poder estabelecidas nos espaços; o território é visto, pois, como um local demarcado e submetido a controle constante. A vertente econômica aponta o território como fonte de recursos, enfatizando as relações entre capital e trabalho. E a vertente cultural ou simbólica, por sua vez, trata do território de forma subjetiva, tomando-o como produto determinado das relações estabelecidas a partir das vivências de grupos sociais.

Costa (2009) defende que espaço e território são termos distintos, e a constituição do território dá-se a partir das ações humanas no espaço. Este é apenas uma matéria-prima, um local que irá transformar-se quando ocorrerem ações intencionais sobre ele, portanto espaço precede ao território. Para Raffestin (1993), essas ações transformam o espaço em território vivido ou "vivido territorial", constituído pela construção, articulação e organização do espaço. O autor denomina "territorialidade" a soma das relações mantidas entre sujeito e espaço. O termo "territorialidade" é utilizado, também, por Saquet (2007), para quem o processo de produção do território é construído pelo movimento histórico no qual o mesmo é apropriado e erigido socialmente como resultado e condição do processo de territorialização. Essa produção é consequência do processo cotidiano de apropriação e domínio social e inscreve-se no estabelecimento das relações socioespaciais. "Os processos sociais e naturais, e mesmo nosso pensamento, efetivam-se na e com a territorialidade cotidiana. É aí, neste nível, que se dá o acontecer de nossa vida e é nesta que se concretiza a territorialidade" (SAQUET, 2007, p. 58). Para o autor, os territórios e as territorialidades

[...] são vividos, percebidos e compreendidos de formas distintas; são substantivados por relações. Homogeneidades e heterogeneidades, integração e conflito, localização e movimento, identidades, línguas e religiões, mercadorias, instituições, natureza exterior ao homem; por diversidade e unidade; (i) materialidade. (SAQUET, 2010, p. 25).

As reflexões teóricas sobre espaço e território constituem um vasto campo de ideias, e identifi- camos, nessas reflexões teóricas, possibilidades de construção de um diálogo com a educação social. Destacamos nessas reflexões elementos como heterogeneidade, multiplicidade e coetaneidade atribuídos ao território (e/ou ao espaço), o reconhecimento da dimensão espacial como constitutiva da vida humana, o movimento de territorialização como apropriação a partir de relações sociais.

Procuramos, a seguir, alinhavar esses elementos à educação social, fundamentando-nos em autores desse campo. O que fazemos pode ser entendido como uma "releitura" de noções construídas por esses autores, a partir de uma perspectiva espaço-territorial.

\subsection{Educação social: releituras}

Paulo Freire, autor referência para a educação popular, afirma que o sujeito apropria-se de um "mundo de que ele mesmo é criador. Vai temporalizando os espaços geográficos. Faz cultura" (FREIRE, 1983, p. 64). Refletimos sobre essa expressão - temporalizar espaços geográficos - e identificamos nela o reconhecimento de espaço e tempo como dimensões da vida humana que transforma o mundo e cria a cultura. Seguindo esse caminho, Freire (1983) afirma que somos esse espaço, ao vivenciá-lo e nos apropriarmos dele. Em seu livro Política e Educação apresenta a Cidade que se faz educativa

[...] pela necessidade de educar, de aprender, de ensinar, de conhecer, de criar, de sonhar, de imaginar de que todos nós, mulheres e homens, impregnamos seus campos, suas montanhas, seus vales, seus rios, impregnamos suas ruas, suas praças, suas fontes, suas casas, seus edifícios, deixando em tudo o selo de certo tempo, o estilo, o gosto de certa época. A Cidade é cultura, criação, não só pelo que fazemos nela e dela, pelo que criamos nela e com ela, mas também é cultura pela própria mirada estética ou de espanto gratuita que lhe damos. A Cidade somos nós e nós somos a Cidade. (FREIRE, 2001, p. 23).

Gohn (2006), ao discutir a educação social, utiliza o conceito "educação não formal". A primazia desse tipo de educação, segundo a autora, é propiciar nos processos de construção de aprendizagem a valorização de saberes coletivos. Destarte procura diferenciá-la de outros tipos de educação, a saber: formal, que classifica como ensino sistematizado 
decorrente de instituições educativas; e informal, na qual o aprendizado ocorre através das relações cotidianas.

A autora considera os movimentos sociais como extremamente significativos nos processos de constituição da educação não formal. No livro O protagonismo da sociedade civil, discute como as forças sociais se deram no Brasil a partir da década de 1980, com movimentos de caráter político contra os regimes militaristas, por meio dos quais a sociedade civil organizava-se em busca da democratização do Estado e sua emancipação. Nessa época a comunidade configurava-se como "uma base territorial dotada de forças políticas à medida que se agregava a associações e movimentos sociais territorializados" (GOHN, 2008, p. 52). Território apresenta-se, segundo a autora, como uma

[...] categoria que vem se impondo no lugar de comunidade porque ela se incorpora à dimensão do espaço/lugar aliada a processos de relações sociais, refere-se ao lugar de memória, da história, da cultura e do poder, da política, portanto. O território passa a ser visto não como uma categoria geográfica social, estática, como num mapa cartorial; ele é visto como uma categoria fundante e articuladora de práticas políticas, como algo histórico. O território é o suporte de práticas identitárias; ele está na base dos conflitos e também na construção dos consensos. (GOHN, 2008, p. 59).

Por sua vez, Graciani (2006) compreende a educação para a sociedade como uma atividade para a vida e que pode ser edificada em todos os espaços sociais. Relaciona os valores dessa educação àqueles da pedagogia freiriana, uma vez que prezam pelo abandono do pensamento ingênuo para a posse de uma reflexão crítica, da saída do apático para o engajamento em uma vivência ativa, da inserção em movimentos sociais e/ou populares com consciência da participação de cada um (a) como ator social capaz de fazer política e combater as disparidades sociais.

É importante compreendermos a educação social como aquela que integra a "objetividade", pelas relações concretas vividas no cotidiano; e a "subjetividade", que estabelece o que é significativo. Graciani (2006) afirma que essa integração comparece no processo de construção do conheci- mento, e define esse processo como dialético, uma vez que parte das práticas (fontes de informação da realidade objetiva) para seguir a um ordenamento de ideias que se relaciona com o concreto. Dessa forma o sujeito é capaz de criar seus conceitos vindos do conhecimento empírico submetido a deduções críticas e transforma todo esse conhecimento em teoria.

A construção do conhecimento teórico, segundo a autora, exige reflexões, pois "trata-se de compreender cada fenômeno particular dentro do movimento que o relaciona com a totalidade social em um movimento histórico concreto dado" (GRACIANI, 2006).

Após a compreensão de sua realidade, o sujeito regressa à prática a fim de transformá-la. Esse movimento de ação/reflexão/ação consolida o conhecimento teórico-prático, fundamental à educação social e que possibilita ao sujeito explorar, cada vez mais, conhecimentos através de reflexões críticas, criando condições diversas para o desenvolvimento de outras capacidades válidas para situações cotidianas.

A aprendizagem na educação social prioriza a vida do sujeito, sua história, seus saberes e o que é significativo, construindo sua totalidade como ser social numa prática libertadora. Essa pedagogia concebe o homem como ser capaz de assumir-se como sujeito de sua história e da história, como agente de transformação de si, do outro e do mundo como fonte de criação, liberdade e construção dos projetos pessoais e sociais, numa dada sociedade, por uma prática social, crítica, criativa e participativa. Pressupõe-se que o mundo é ao mesmo tempo produtor e produto do homem, e que, ao transformá-lo, engenha em si mesmo a sua própria transformação, num processo dialético contínuo e permanente (GRACIANI, 2006).

Destacamos das reflexões de Freire, Gohn e Graciani a perspectiva da transformação na qual comparecem os elementos da conscientização, ação/reflexão e organização social, a transformação dos sujeitos e da sociedade. Tais elementos dialeticamente relacionados configuram-se como objetivo, metodologia, consequência e sentido da educação social. Ao buscarmos o diálogo com os estudos territoriais, encontramos ênfase semelhante. 
Gadotti (1991) ressalta que a natureza por si mesma transforma-se em um movimento de reorganização e acomodação, porém o sujeito faz suas intervenções que mudam a natureza e, por conseguinte, a sociedade. "Dessa forma ele transforma o meio natural em meio cultural (científico e técnico). Da mesma forma ele intervém sobre a sociedade de homens, na direção de um horizonte mais humano" (GADOTTI, 1991, p. 68).

Os estudos territoriais trazem também a ideia de que os espaços se modificam conforme a necessidade da sociedade. A busca por recursos de sobrevivência implica a atividade humana que, uma vez exercida no espaço, provoca mutações, o que nos permite pensar que a transformação social é um dos aspectos do estabelecimento e das transformações dos territórios. As contribuições de Soja e Freire explicitam aspectos interessantes da proximidade entre os estudos territoriais e a educação social. Para Soja (1993), somente o ser humano consegue isolar-se do mundo, distanciar-se para poder observar seu espaço. Nesse afastamento conscientiza-se de sua existência e se objetiva no espaço novamente, para desta vez mudar a sua realidade.

A objetivação, o desligamento e o distanciamento, entretanto, são somente uma dimensão existencial da consciência, base apenas para uma definição mínima do ser. Ser humano não é somente criar distâncias, mas tentar transpô-las, transformar a distância primeva através da intencionalidade, da emoção, do envolvimento e do apego. Assim, a espacialidade humana é mais do que o produto de nossa capacidade de nos separarmos do mundo, de uma Natureza primitiva, para contemplarmos sua plenitude distante e nossa separação (SOJA, 1993, p. 162).

Freire (1980) considera que o ato de refletir a ação é intrinsecamente humano, pois permite que a pessoa se afaste de sua realidade para compreendê-la e para agir sobre ela após a tomada de consciência, no sentido de sua própria transformação e do mundo no qual vive.

Uma das características do homem [e da mulher] é que somente ele é homem [e mulher]. Somente ele é capaz de tomar distância frente ao mundo. Somente o homem pode distanciar-se do objeto e admirá-lo. Objetivando ou admirando - admirar se torna aqui no sentido filosófico -, os homens são capazes de agir conscientemente sobre a realidade objetivada. É precisamente isso, a 'práxis humana', a unidade indissolúvel entre minha ação e minha reflexão sobre o mundo (FREIRE, 1980, p. 26, grifo do autor).

Portanto, pensar em território e educação social é voltar-se aos modos pelos quais a humanidade se apropria do espaço e o transforma, em um movimento histórico produtor de cultura e educação. Chegamos assim ao terceiro elemento da reflexão proposto neste artigo: o currículo, o que nos permite identificar outros movimentos teóricos nas relações entre educação social e território.

\section{Currículo, educação social e território}

Em nossas reflexões anteriores procuramos explicitar o diálogo entre educação social e território, através de elementos tais como a espacialidade constitutiva da vida humana, a heterogeneidade, a multiplicidade, a coetaneidade, as relações de poder, a reflexão sobre o vivido. São esses elementos que também identificamos nas experiências educativas em espaços não escolares, as quais se fazem no próprio processo de constituição dos grupos. $\mathrm{O}$ ato de organizar-se coletivamente na defesa dos direitos, na busca de concretização de sonhos, na construção cotidiana pelo direito à vida, a terra e ao trabalho; a luta por se fazer reconhecer como grupo, as reexistências cotidianas são, pois, movimentos educativos.

Arroyo (2003), em seu texto Pedagogias em movimento: o que temos a aprender dos movimentos sociais?, apresenta-nos a centralidade do sujeito em sua luta histórica pela vida, pelas condições mais justas de trabalho, pelo direito à saúde, moradia, alimentação. É esta luta que vemos ser travada no interior das experiências educativas nos movimentos sociais. Nesse processo, mulheres e homens educam-se a si mesmos (as), participam de processos de construção coletiva no qual se propõem a educar outras mulheres e outros homens.

Arroyo (2003, p. 1-2) aponta que nas décadas de 1970 e 1980, no Brasil, várias investigações mostraram "a influência dos movimentos sociais na conformação da consciência popular do direito à educação básica, à escola pública". Além do 
entendimento da educação como um direito, que veio se forjando no interior dos movimentos sociais desde as décadas assinaladas por Arroyo (2003), aos poucos, à medida que esses enfrentamentos diminuem (e surgem outros) forja-se, também, a preocupação com o direito à educação. Nesse momento, no Brasil, se conheciam os enfrentamentos com a evasão, a repetência, o grande número de crianças "fora das escolas".

Por outro lado, encontramos na sociedade sinais de preocupação com os milhões de jovens e adultos que têm direito à educação básica. ONGs, igrejas e cultos afro-brasileiros, sindicatos e movimentos sociais, especificamente os movimentos sociais do campo como o Movimento dos Trabalhadores Sem Terra (MST), criam propostas voltadas à educação de jovens e adultos (ARROYO, 2005).

No Brasil, o MST compreende que a conquista pelos direitos deve envolver também o direito à educação, e passava a reivindicar (e conquistar), desde os anos 1980, em seus acampamentos, escolas para crianças e para pessoas jovens e adultas e, mais recentemente, um curso superior específico para formação de professores (as) nascidos (as) no interior do próprio movimento (ROCHA; MARTINS, 2009).

São, pois, as experiências educativas escolarizadas que acontecem nesses espaços (em acampamentos de trabalhadores Sem Terra, em associações cooperativas organizadas, em associações de mulheres, em associações de catadores (as) de materiais recicláveis, em grupos ribeirinhos, quilombolas, grupos de moradores de rua etc.) que nos aproximam das discussões sobre o currículo.

Em novos alinhavos buscamos em autores do currículo elementos que nos permitem refletir sobre educação social/território/currículo, e tais elementos e reflexões levam-nos a nos aproximar de questões debatidas na perspectiva crítica do currículo ${ }^{1}$ tomado, pois, como um "[...] artefato social e cultural. Isso significa que ele é colocado na moldura mais ampla de suas determinações sociais, de sua história, de sua produção contextual" (MOREIRA; SILVA, 2009, p. 8). É nessa perspectiva que encontramos eco das discussões que se fazem presentes nas tramas da educação social/território,

1 Para aprofundar sobre as teorias críticas do currículo, sugerimos conferir Silva (2004). em torno de três eixos identificados como centrais para as teorias críticas: ideologia, cultura e poder (MOREIRA; SILVA, 2009).

\subsection{Ideologia, cultura e poder}

Oliveira (2012) defende o currículo como criação cotidiana dos praticantes e aponta as possibilidades de que o mesmo contribua para a emancipação social. A autora afirma o currículo cotidiano como resultado "de diálogos e enredamentos entre conhecimentos formais - advindos das diferentes teorias com as quais entraram em contato em diversos momentos e circunstancias de suas vidas - e outros conhecimentos aprendidos pelos praticantespensantes por meio de outros processos" (OLIVEIRA, 2012, p. 8, grifo do autor).

Considerando o sujeito como ser de práxis e reflexivo, Oliveira (2012, p. 9, grifo do autor) utiliza a noção de circularidade de culturas para compreender

[...] os modos por meio dos quais ideias, documentos e debates criados em determinado espaçotemposocial e cultural dialogam permanentemente com outros espaçostempos, sendo apropriados e modificados pelos sujeitos sociais, exatamente porque, mais do que consumi-los, estes os criam e recriam, usando-os de modos próprios, enredando-os aos seus conhecimentos, valores, ideias, crenças e trajetórias pessoais e profissionais anteriores.

Entender o currículo como produção do cotidiano traz perspectivas emancipatórias. Salientando a indissociabilidade entre epistemologia e política, Oliveira (2012) argumenta que a emancipação, de caráter social, se dá por meio de relações sociais, no reconhecimento de dicotômicos saberes, tempos, espaços, cultura, recursos e produções. Portanto, compreender o currículo nesses aspectos é pensá-lo como criação cotidiana dos praticantespensantes, não se limitando àqueles que o fazem dentro de instituições formais, mas se estende aos diversos espaços sociais nos quais práticas curriculares emancipatórias são "fruto dos diversos modos de inserção social [dos sujeitos] no mundo, inclusive no campo do embate político e ideológico que habita a sociedade" (OLIVEIRA, 2012, p. 12). 
Sobre a ideologia, Moreira e Silva (2009, p. 23) afirmam que a mesma "está relacionada às divisões que organizam a sociedade e às relações de poder que sustentam essas divisões". Os autores defendem como questão primordial da ideologia a visão de mundo que é transmitida, pois esta não é nada mais que os interesses de uma determinada organização social. Pensando assim, a ideologia não se afasta do currículo, pois opera significativamente nas relações sociais e de poder. O currículo é, pois, palco de ideologias.

Moreira e Silva (2009) identificam nas concepções críticas os vínculos entre cultura e currículo. O currículo não pode ser transmitido e recebido de forma que possamos nos acomodar com os conhecimentos impostos, já que por lançar cultura certamente acarreta dimensões políticas. Quando falamos de dimensão política não podemos nos esquivar das relações de poder que compõem as discussões sobre currículo, nos estudos curriculares, educacionais e territoriais.

Nesse último as relações de poder partem dos diferentes interesses que se tem sobre o espaço. Em sua disputa podem ocorrer organizações de grupos que pretendem defender interesses em comum. A mobilização para a tomada de poder implica aos sujeitos a conscientização do modo como vivem e a busca de melhoria das condições de vida. Isso exige a leitura de mundo, objetivo primeiro da educação social.

Já dizia Freire (1984) que toda educação é política, pois é capaz de transformar tanto a vida individual do sujeito quanto o seu estar na sociedade; jamais poderia ser, portanto, uma educação marcada pela neutralidade quando se trata da formação integral do sujeito; muito menos o ato político poderá ser evasivo de signos educativos.

Tanto no caso do processo educativo quanto no ato político, uma das questões fundamentais seja a clareza em torno de a favor de quem e do quê, portanto contra quem e contra o quê, fazemos a educação, e de a favor de quem e do quê, portanto contra quem e contra o quê, desenvolvemos a atividade política. Quanto mais ganhamos esta clareza através da prática, tanto mais percebemos a impossibilidade de separar o inseparável: a educação da política. Entendemos então, facilmente, não ser possível pensar sequer a educação sem que seja atento à questão do poder (FREIRE, 1984).

As relações de poder são centrais na teorização crítica (MOREIRA; SILVA, 2009). O sujeito é, portanto, um ser de relações e precisa delas para viver em sociedade. O poder emerge nas interações que ocorrem entre as pessoas e no meio nos quais vivem. Assim, o poder não se configura em algo, como uma propriedade, mas se constitui como relações de força nas práticas sociais.

Sem relações não há existência de poder, e para Gohn (2008), o convívio em comunidade indica poder local, uma força organizada no cerne dos movimentos sociais e expressa "nos discursos, enquanto forma de conhecimento, mas também o significado do mundo" (GOHN, 2008, p. 50). Os poderes construídos pela comunidade tendem a priorizar as diversidades culturais, estabelecendo vínculos com aspectos sociais, políticos e culturais.

As relações de poder são frequentemente abordadas pelos autores dos estudos territoriais. Para Costa (2009), essas relações desenvolvem-se no espaço, em um processo no qual as práticas sócio-históricas estendem-se às dimensões políticas e solidificam-se no espaço situado. Ao adotar uma perspectiva ampla sobre poder, o autor mostra sua ligação nos âmbitos econômicos e culturais ou simbólicos. O território envolve

[...] uma dimensão simbólica, cultural, através de uma identidade territorial atribuída pelos grupos sociais, como forma de 'controle simbólico' sobre o espaço onde vivem (sendo também, portanto, uma forma de apropriação, e uma dimensão mais concreta, de caráter político-disciplinar [e político-econômico, deveríamos acrescentar]: a apropriação e ordenação do espaço como forma de domínio e disciplinarização dos indivíduos). (COSTA, 2009, p. 94, grifo do autor).

Compreende-se, desse modo, que no território a noção de poder não se limita à conservação de uma ordem, mas expande-se para estabelecer identidades constituídas pela adoção de signos que criamos a partir de nossas vivências culturais sob a influência de contextos políticos e econômicos.

\subsection{Outras conexões}

A noção de território está presente na reflexão de Arroyo (2011), constituindo-se, inclusive, o mote 
para o título do livro Currículo, Território em Disputa. Neste livro ele reconhece o espaço como local de memórias e histórias edificadas pelas produções humanas por meio das relações sociais e de poder, e ao nos interrogar sobre "em que territórios e em que disputas conformamos quem somos?" (ARROYO, 2011, p. 9). O currículo é, pois, território em disputa (de saberes, de práticas, de culturas, de identidades hegemônicas, de diferenças...).

Há de se considerar na construção do currículo, o sujeito e suas condições na vivência dos espaços e os saberes dessas vivências, atentando-se para o fato de que o espaço situado pelo sujeito é composto de historicidades, posses, desterritorializações, reterritorializações, multiterritórios, precariedade, territorialidades, apropriações e produções.

$\mathrm{O}$ autor sugere uma viagem a outras geografias, que permitam evidenciar os espaços como territórios de vivências transformadoras. As experiências sociais devem ser reconhecidas como produtoras de saberes, e precisam ser refletidas como tais nos currículos - saberes das infâncias, das adolescências, das juventudes, de mulheres e homens, que se fazem ausentes nas experiências educativas (em espaços escolares e não escolares) (ARROYO, 2011).

Arroyo (2011) aponta a ausência dos sujeitos nos ensinos coletivos, sendo estes ignorados como atores de histórias, de memórias coletivas e ocultados enquanto pessoas que se fazem presentes no espaço, na produção de riquezas, produtores de conhecimentos e de culturas.

Silva (2004) observa que o currículo está envolvido com o que somos, e cria vínculos com as questões identitárias. Discussões sobre identidade apresentam-se nos estudos territoriais, sendo definida por autores como Saquet (2010) e Raffestin (1993) como a representação de relações criadas por indivíduos ou grupos que compartilham em um mesmo espaço valores éticos, morais e materiais que direcionam os comportamentos da sociedade. Este processo contínuo configura-se através de espaço e tempo.

As identidades são constituídas através de tudo o que é significante para o indivíduo, por criarem códigos culturais denominados de signos, imprimindo no território vínculos afetivos. Nas práticas cotidianas a sociedade potencializa-se para a afirmação da identidade social tomando como referência o seu território em seus diferentes espaços e tempos. Desta maneira o poder simbólico fundamenta-se em representações e ideologias que efetivam a identidade territorial.

As formações territoriais envolvem também a constituição de territorialidades "intimamente relacionada [s] ao modo como as pessoas usam a terra, como organizam o espaço e como dão significados ao lugar" (SACK, 1968 apud SAQUET, 2010 , p. 83); estas são frequentemente tratadas como aspectos identitários.

Os espaços são, portanto, fundamentais para a construção de identidades, uma vez que são dotados de tradições, sentimentos, emoções, significados e culturas que se configuram na subjetividade do sujeito em sociedade.

Os estudos no campo da educação social apresentam que as relações do sujeito com seu meio, a consciência acerca da realidade e a ação sobre a realidade são processos vinculados às questões identitárias. Educação e identidade fundem-se com força maior para que o indivíduo se situe no espaço e consiga definir o que é significativo a ele, para que a sua tomada de consciência se volte à sua realidade e ao que lhe interessa.

Por sua vez, a educação social também está relacionada à construção de identidade coletiva. Gohn (2008) analisa a participação dos sujeitos em grupos sociais como passo principal para determinar significados, respostas e ações, em um processo de reconhecimento de identidade social.

O conjunto de percepções e de visões de mundo que um grupo constrói no processo de experiência histórica ao atuarem coletivamente, aliado as representações simbólicas que também constroem ou adotam, são a parte mais relevante da cultura política de um grupo porque é a partir desses elementos que o grupo constrói sua identidade. (GOHN, 2008, p. 34 , grifo do autor).

Quando o sujeito apropria-se de significados, estabelece o seu referencial dentro de valores culturais e políticos vindos de uma trajetória de vida. A busca desses ideais leva a sociedade a reconhecer-se como portadora de autonomia, de direitos igualitários e "novos sujeitos de poder." (GOHN, 2008, p. 9). 
Além do caráter identitário, a perspectiva crítica do currículo vem evidenciar um sujeito que argumenta, contesta, mobiliza implicado, portanto, em processos de conscientização. Nessa perspectiva o sujeito não pode permanecer na neutralidade que remete ao descomprometimento consigo mesmo e com o mundo, pois assim torna-se um ser alienado.

Ao relacionar o espaço vivenciado e currículo, Arroyo (2011, p. 334) indaga que "O espaço visto de longe pode ser poético e formoso, o espaço vivido é outro. Este está presente nos currículos?”. Trabalhar pedagogicamente relacionando vivências e comovendo para a atribuição de significados é valorizar histórias concretas. Por essa razão o currículo deve colocar em foco o sujeito como protagonista de sua história na vida social, reconhecendo suas lutas, seus valores, suas culturas, suas vivências e leituras de mundo, reconhecendo-o como pessoa de direitos e de saberes e contemplá-lo tanto em sua objetividade quanto em sua subjetividade.

No campo da educação social, a objetividade e a subjetividade concretizam-se nas vivências cotidianas, nas (re) produções humanas efetivadas no espaço onde se habita, construindo e reproduzindo a materialidade por meio das ações humanas. Tais ações, essenciais para transformar um lugar que seja favorável à vida das pessoas, são também impregnadas de significados, de subjetividade ou imaterialidade, em um processo de tomada de consciência do sujeito em relação ao espaço.

Por sua vez, os estudos territoriais abordam o território como espaço físico, considerando-o em sua materialidade (SAQUET, 2010), mas vão além ao afirmar que a paisagem (material) é construída por meio das produções humanas e nesse processo, como produto dessa produção, são impregnados nos territórios a imaterialidade que se compõe de sentimentos, emoções, afetividades, símbolos (SAQUET, 2010). É nesse sentido que se afirma o material e imaterial como complementares na formação territorial.

Como espaço socialmente produzido, a espacialidade pode ser distinguida do espaço físico da natureza material e do espaço mental da cognição e da representação, cada um dos quais é usado e incorporado na construção social da espacialidade, mas não pode ser conceituado como seu equivalente (SOJA, 1993, p. 147).
Para Saquet (2010), objetividade e subjetividade levam à compreensão de que o território é construído por meio das relações que estabelecem na materialidade do espaço,

[...] desta forma, a materialidade do território não está na sua percepção e descrição mais banal e superficial, efetivada no século passado através de uma geografia não reflexiva de derivação positivista. Ao contrario, a materialidade do território exprime-se nas relações intersubjetivas derivadas, em última instância, da necessidade de produzir e de viver que, ligando os sujeitos humanos à materialidade do ambiente, provoca interações entre si, como membros de uma sociedade. O território, assim, resulta como conteúdo, meio e processo de relações sociais. Essas relações sociais que são, ao mesmo tempo, materiais, substantivam o território. (SAQUET, 2010, p. 8).

Com as discussões apresentadas nesta seção queremos mostrar que o espaço não é o dado, o morto, o fixo, o imutável, como alerta Foucault (2009), e que, portanto, é imprescindível considerá-lo como constitutivo das experiências educativas populares, pois "não vivemos numa espécie de vazio, no interior do qual se poderiam situar os indivíduos e as coisas [...] vivemos no interior de um conjunto de relações que definem posicionamentos irredutíveis uns aos outros e absolutamente impossíveis de ser sobrepostos" (FOUCAULT, 2009, p. 414).

\section{Para concluir: indagações}

As legendas dos mapas são tão belas que dispensam as viagens. Você está louca, dizem-me, um mapa é um mapa. Não estou, respondo. O mapa é certeza de que existe o LUGAR, o mapa guarda sangue e tesouros. Deus nos fala no mapa com sua voz geógrafa. (PRADO, 1991, p. 266, grifo do autor).

Adélia Prado, no fragmento acima, fala dos mapas - o mapa como a certeza de que o lugar existe, mas guarda sangue, tesouros e, poderíamos acrescentar, memórias, histórias, experiências, embates, vivências e sobrevivências. Por isso a centralidade do espaço no estabelecimento das relações na vida social, pois ele é palco e substrato das produções humanas - relações e interações. Essa perspectiva favorece uma reflexão crítica a partir da compreensão de uma realidade dialética que articula os 
sujeitos e o meio no qual vivem, e é nesse sentido que vislumbramos a fertilidade das discussões de território para a prática pedagógica e pesquisas no campo da educação, para além da educação social e do currículo, destacados neste texto.

Nesse sentido empreende-se um movimento de pensar os sujeitos como pessoas (crianças, adolescentes, jovens, adultos) situadas no espaço e tempo, com marcadores sociais diversos (gênero, raça, etnia, religioso, idade...), habitantes das cidades e do campo, das periferias ou "sem espaços de vida", quer seja na cidade ou no campo, e os considerarmos como no dizer de Freire (1980), pessoas concretas, que vivenciam em um lugar contextos sociais e culturais de sua época, marcadas pelas lutas, embates e, muitas vezes, pelas mazelas sociais.

Por isso, Freire (2001) diz serem mulheres e homens seres de "raízes espaço-temporais". Dessa forma a Educação se volta (ou não?) para as dimensões ontológicas das pessoas, considerando suas condições de vida nos espaços, interações e necessidades.
Miguel Arroyo (2003), discutindo as relações entre movimentos sociais e educação, faz um alerta a pesquisadores e pesquisadoras que se propõem a investigar relações educativas no interior desses movimentos e suas implicações para a pesquisa e a prática em educação. São essas palavras que tomamos emprestado do autor para concluirmos este artigo, por considerar que esse alerta contribui, também, para pesquisadoras e pesquisadores que se debruçam sobre o vivido territorial, e força-nos a novas indagações sobre a produção do conhecimento, como pesquisadoras e pesquisadores que refletem sobre vividos, mas que, também, se situam como pessoas em vividos territoriais:

Ter como objeto de pesquisa e de reflexão as artes e saberes aprendidos nessas situações totalizantes e limites da condição humana seria uma grande contribuição para superar as visões tão pontuais, didáticas, metodológicas e gerenciais que tanto tem distraído e esterilizado o pensamento e a pratica escolar e extra-escolar. (ARROYO, 2003, p. 36).

\section{REFERÊNCIAS}

ARROYO, Miguel G. Currículo, território em disputa. Petrópolis, RJ: Vozes, 2011.

Pedagogias em movimento: o que temos a aprender com os movimentos sociais? Currículo sem Fronteiras, Belo Horizonte, v. 3, n. 1, p. 28-49, jan./jun. 2003. Disponível em: <http://www.curriculosemfronteiras. org/vol3 >. Acesso em: 18 out. 2014.

Educação de jovens e adultos: um campo de direitos e de responsabilidade pública. In: SOARES, Leôncio; GIOVANETTI, Maria A.; GOMES, Nilma L. (Org.). Diálogos na educação de jovens e adultos. Belo Horizonte: Autêntica, 2005. p. 19-50.

BRASIL. Ministério da Educação. Resolução CNE/CEB nº 2, de 19 de maio de 2010. Diário Oficial [da] República Federativa do Brasil, Poder Executivo, Brasília, DF, 20 maio 2010. Seção 1, p. 20.

BRUNET, Roger. Et al. Les mots de La Géographie. Paris: La Documentation Française, 1993.

CHARLOT, Bernard. A pesquisa educacional entre conhecimentos, políticas e práticas. Revista Brasileira de Educação, v. 11, n. 31, p. 7-18, jan./abr. 2006.

COSTA, Rogério H. da. O mito da desterritorialização: do "fim dos territórios" à multiterritorialidade. 3. ed. Rio de Janeiro: Bertrand Brasil, 2009.

FAZENDA, Ivani, C. A. (Org.). Didática e interdisciplinaridade. 9. ed. Campinas, SP: Papirus, 2005.

FRANCO, Maria Amélia S. Pedagogia como ciência da educação. São Paulo: Papirus, 2003.

FREIRE, Paulo. Conscientização: teoria e prática da libertação: uma introdução ao pensamento de Paulo Freire. 3. ed. São Paulo: Moraes, 1980.

Educação e mudança. Rio de Janeiro: Paz e Terra, 1983.

A importância do ato de ler: em três artigos que se completam. São Paulo: Cortez, 1984. 
Política e educação: ensaios. 6. ed. São Paulo: Cortez, 2001.

FOUCAULT, Michel. Outros espaços. In:

Estética: literatura e pintura, música e cinema - ditos e escritos. Rio de Janeiro: Forense Universitária, 2009. v. 3. p. 411-422.

GADOTTI, Moacir. Educação e poder: introdução à pedagogia do conflito. 10. ed. São Paulo: Cortez, 1991.

Educação popular, educação social, educação comunitária: conceitos e práticas diversas, cimentadas por uma causa comum. In: CONGRESSO INTERNACIONAL DE PEDAGOGIA SOCIAL, 4., 2012, São Paulo. Anais eletrônicos... São Paulo, 2012. Disponível em: <http://www.proceedings.scielo.br/scielo.php?pid>. Acesso em: 26 nov. 2014.

GOHN, Maria da Glória. Educação não-formal na pedagogia social. CONGRESSO INTERNACIONAL DE PEDAGOGIA SOCIAL, 1., 2006, São Paulo. Anais eletrônicos... São Paulo: Universidade de São Paulo, 2006. Disponível em: <http://www.proceedings.scielo.br/scielo>. Acesso em: 20 out. 2014.

O protagonismo da sociedade civil: movimentos sociais, ONGs e redes solidárias. 2. Ed. São Paulo: Cortez, 2008

GRACIANI, Maria Stela Santos. Pedagogia social: impasses, desafios e perspectivas em construção. CONGRESSO INTERNACIONAL DE PEDAGOGIA SOCIAL, 1., 2006, São Paulo. Anais eletrônicos... São Paulo: Universidade de São Paulo, 2006. Disponível em: <http://www.proceedings.scielo.br/scielo>. Acesso em: 20 mar. 2014.

MASSEY, Doreen. Pelo espaço: uma nova política da espacialidade. Rio de Janeiro: Bertrand Brasil, 2007.

MOREIRA, Antônio F. B; SILVA, Tomaz Tadeu da (Org.). Currículo, cultura e sociedade. 11. ed. São Paulo: Cortez, 2009.

OLIVEIRA, Inês Barbosa de. O currículo como criação cotidiana. Rio de Janeiro: FAPERJ, 2012.

PRADO, Adélia. Poesia Reunida. São Paulo: Siciliano, 1991.

PIMENTA, Selma Garrido. Pedagogia, ciência da educação? São Paulo: Cortez, 1998.

RAFFESTIN, Claude. Por uma geografia do poder. São Paulo: Ática, 1993. (Série Temas: Geografia e Política, v. 29).

ROCHA, Maria Isabel Antunes; MARTINS, Aracy Alves (Org.). Educação do campo: desafios para a formação de professores. Belo Horizonte: Autêntica, 2009.

SAQUET, Marco Aurélio. As diferentes abordagens do território e apreensão do movimento e da (i) materialidade. Geosul, Florianópolis, v. 22, n. 43, p. 55-76, jan./jun. 2007.

Abordagens e concepções de território. 2. ed. São Paulo: Expressão Popular, 2010.

SILVA, Tomaz Tadeu. Documentos de identidade: uma introdução às teorias do currículo. 2. ed., $7^{\mathrm{a}}$ reimp. Belo Horizonte: Autêntica, 2004.

SOJA, Edward W. Geografias pós-modernas: a reafirmação do espaço, na teoria social. Rio de Janeiro: Zahar, 1993.

THIESEN, Juares da Silva. Revista Brasileira de Educação, v. 13, n. 39, p. 545-553, set./dez. 2008.

Recebido em: 01.12.2014

Aprovado em: 10.04.2015 